\title{
Artigo/Article
}

\section{Perfil de prescrições e uso de antibióticos em infecções comunitárias}

\author{
Prescription patterns and antibiotic use in community-based infections \\ Fernando de Sá Del Fiol ${ }^{1,3}$, Luciane Cruz Lopes ${ }^{1,3}$, Maria Inês de Toledo ${ }^{2}$ e Silvio Barberato-Filho ${ }^{2,3}$
}

\section{RESUMO}

Introdução: $\mathrm{O}$ objetivo deste estudo foi conhecer os padrões de utilização de antibióticos no município de Sorocaba, avaliando o diagnóstico referido, a terapêutica empregada e sua utilização. Métodos: Utilizou-se um instrumento de avaliação aplicado por 12 meses em usuários de antibióticos. Foram coletados dados de 403 usuários e referiram-se à: informações sociodemográficas e de saúde, diagnóstico e terapêutica. Resultados: Encontrou-se grande utilização e a maior utilização prévia na faixa etária de 0-10 anos $(\mathrm{p}<0,05)$. As infecções com envolvimento pulmonar foram as mais citadas $(\mathrm{p}<0,05)$ e as penicilinas, os fármacos mais utilizados, presentes em $45,1 \%$ das prescrições. Tempo médio de terapêutica ( 8,9 dias) esteve abaixo do preconizado para otites. Em sinusites, $22 \%$ das prescrições não orientaram para o uso recomendado (10 dias). Conclusões: A inexistência e não utilização de protocolos terapêuticos têm resultado em grande diferença nos padrões de prescrição, levando a insucesso terapêutico e recidiva de infecções - situações frequentemente encontradas neste estudo.

Palavras-chaves: Antibióticos. Prescrição. Infecções bacterianas. Resistência bacteriana.

\begin{abstract}
Introduction: The aim of this study was to find out about the patterns of antibiotic use in the municipality of Sorocaba, through evaluating the reported diagnosis and the therapy used. Methods: An evaluation tool was applied among antibiotic users over a 12-month period. Sociodemographic data and information relating to health, diagnosis and therapeutics were gathered in relation to 403 users. Results: Great present use and the greatest previous use was found in the $0-10$ year-old age group $(p<0.05)$. Infections with lung involvement were the ones most mentioned $(\mathrm{p}<0.05)$ and penicillins were the drugs most used, present in $45.1 \%$ of the prescriptions. The mean duration of therapy for otitis ( 8.9 days) was below the recommendation. For sinusitis, $22 \%$ of the prescriptions did not give guidance regarding recommended use (10 days). Conclusions: The lack and/or nonuse of therapeutic protocols resulted in great differences in prescription patterns, thereby leading to therapeutic failure and recurrence of infections, which were situations frequently found in this study.
\end{abstract}

Key-words: Antibiotics. Prescriptions. Bacterial infections. Bacterial resistance.

1.Departamento de Farmacologia. Universidade de Campinas, Campinas, SP. 2. Universidade de São Paulo, São Paulo, SP. 3. Programa de Pós-Graduação stricto sensu em Ciências Farmacêuticas, Universidade de Sorocaba, Sorocaba, SP.

Endereço para correspondência: Prof. Fernando de Sá Del Fiol. Rua Paulo Setúbal 344, 18520-000 Cerquilho, SP.

Tel: 5515 8118-6000; Fax: 5515 2101-7073

e-mail: fernando.fiol@uniso.br

Recebido para publicação em 16/07/2009

Aceito em 13/01/2010

\section{INTRODUÇÃO}

A resistência de bactérias aos antibióticos disponíveis clinicamente se tornou um problema de saúde pública em todo mundo. Além disso, o custo financeiro de uma terapia fracassada por conta de microrganismos resistentes é muito grande, onerando ainda mais os sistemas públicos de saúde. Bactérias resistentes geram nova consulta, novos exames diagnósticos, nova prescrição, sem contar a provável internação e ocupação de leitos hospitalares. Estima-se que, apenas nos Estados Unidos, o custo com resistência bacteriana está em torno de 4 a 5 bilhões de dólares anualmente ${ }^{1}$.

O grande responsável pela disseminação dos genes de resistência e, por conseguinte de microrganismos resistentes, é sem dúvida o próprio homem; seja pela atitude inconsequente ou pela falta de informação, o uso irracional de antimicrobianos tem aumentado, a despeito de todas as publicações, campanhas e informações acerca do fato ${ }^{2}$.

O uso indiscriminado e irresponsável de antibióticos, terapêutica ou profilaticamente, humano ou veterinário, passando ainda pelo uso no crescimento animal e propósitos agrícolas, tem favorecido a pressão seletiva, mostrando como resultado a seleção e predominância de espécies bacterianas cada vez mais resistentes ${ }^{3}$.

No Brasil, o uso indiscriminado de medicamentos em geral, leva-nos a situações cada vez mais preocupantes. Haak ${ }^{4}$ realizou estudo sobre padrões de utilização em duas comunidades no estado da Bahia, incluindo 62 famílias selecionadas ao acaso. $\mathrm{O}$ autor constatou que praticamente todos os medicamentos utilizados no contexto da automedicação pertencem aos grupos dos antibióticos, analgésicos, vitaminas e anticoncepcionais.

Além do uso de antibióticos sem prescrição, ainda é muito grande e desnecessário o uso orientado por prescritores. O uso inadequado em infecções 
de etiologia viral já foi extensamente discutido na literatura e dados recentes dão conta de que em aproximadamente 55\% das infecções de etiologia viral são administrados, inocuamente, antibióticos, com finalidade profilática ou terapêutica ${ }^{5}$.

Estudo prévio conduzido na Cidade de São Paulo verificou que $68 \%$ dos antibióticos prescritos para crianças menores de sete anos com infecções respiratórias agudas eram inadequados; a maioria foi indicada para o tratamento do resfriado comum. Nos casos de otites e amidalites, os maiores problemas encontrados foram: a escolha de antibióticos de amplo espectro e/ou alto custo, tempo curto de tratamento, erros no intervalo entre as doses ou prescrição de antibióticos ineficazes para a erradicação do estreptococo da orofaringe ${ }^{6}$. O manejo inadequado da terapêutica antimicrobiana tem nos levado a dados assustadores nos níveis de resistência bacteriana. O principal patógeno associado às infecções aéreas, o Streptococcus pneumoniae, aumentou de 2,5 para $13 \%$ seus níveis de resistência aos derivados penicilínicos ${ }^{7}$.

Outro grande desafio quando se fala em uso racional de antibióticos diz respeito à qualidade da informação que o paciente detém para o uso do medicamento. A falta de informações durante a consulta, seguida por pouca ou nenhuma orientação no ato da dispensação do medicamento, faz com que o usuário abandone o tratamento precocemente, perca administrações ou ainda os utilize desnecessariamente ${ }^{7}$.

A proposta do presente trabalho foi estudar o perfil de prescrições de antimicrobianos em uma grande cidade brasileira, com o objetivo de conhecer o padrão de utilização desses medicamentos. Os resultados obtidos poderão subsidiar campanhas educativas para promover o uso racional de antimicrobianos diminuindo os custos para o Sistema de Saúde e os níveis de resistência bacteriana.

\section{MÉTODOS}

Foi utilizada pesquisa exploratória, a partir de um questionário estruturado com 70 questões, abertas e fechadas, aplicado em usuários de antibióticos no momento da dispensação. $\mathrm{O}$ estudo foi realizado no município de Sorocaba, Estado de São Paulo, Brasil, que possui 559.157 habitantes e índice de desenvolvimento humano de $0,828^{8}$. O número de entrevistados foi estimado em 400, a partir do cálculo de amostra simples para população infinita (quando não é possível saber o número exato de indivíduos), descrito por Cochran ${ }^{9}$.

Os dados foram coletados entre janeiro e dezembro de 2006, por três bolsistas de Iniciação Científica da Universidade de Sorocaba, em três locais distintos: a) Farmácia Escola "Vital Brazil" (Farmácia Universitária), com atendimento e doação de medicamentos à população de Sorocaba e Região; b) Farmácia de uma Unidade Básica de Saúde, da região central da cidade, que atende 29 mil pessoas e realiza cerca de 6 mil consultas/mês; c) Farmácia comercial, localizada também na região central da cidade.

A escolha destes locais procurou representar as várias possibilidades de dispensação de medicamentos para a população do município.

Responderam ao instrumento, usuários que se apresentaram nos locais de coleta de dados munidos de prescrição médica ou odontológica contendo um ou mais antibióticos. Nos usuários com menos de 18 anos, o questionário foi aplicado no responsável que se fez presente. Profissionais de saúde foram excluídos.
O instrumento foi dividido em quatro partes: a) informações sobre o paciente (perfil e hábitos); b) informações sobre a prescrição e a consulta; c) informações sobre o quadro clínico que levou o paciente a buscar atendimento médico; d) informações do usuário sobre a utilização de antibióticos.

Os resultados obtidos foram transportados para um banco de dados utilizando o programa Access"e para comparação entre as proporções encontradas foi utilizado o teste $\mathrm{Z}$ com nível de significância de $5 \%$.

\section{Ética}

O presente trabalho foi submetido e aprovado pelo Comitê de Ética em Pesquisas do Centro de Ciências Médicas e Biológicas de Sorocaba da Pontifícia Universidade Católica de São Paulo.

\section{RESULTADOS}

O instrumento foi aplicado em 403 usuários que se apresentaram nos locais de coleta com prescrição de antimicrobianos.

A Tabela 1 apresenta as características demográficas e de saúde da população estudada. Ao analisarmos as faixas etárias dos usuários de antibióticos deste estudo, nota-se um grande percentual de utilização $(28,3 \%)$ na faixa etária de $0-10$ anos $(p<0,05)$, que representou mais que o dobro de qualquer outra faixa etária estudada. Com relação a doenças crônicas preexistentes e uso de outro medicamento, pôde-se observar aumento diretamente proporcional à faixa etária.

A Tabela 2 apresenta a experiência prévia da população estudada com relação ao uso de antibióticos nos seis meses anteriores à coleta de dados. Nota-se que a maior frequência de prescrição ocorreu nas faixas etárias 0 a 10 anos (44,7\%), 40 a 50 (52\%) e 60 ou mais $(38,8 \%)$, diferindo apenas da faixa etária 20 a 30 anos $(20,3 \%)$ $(\mathrm{p}<0,05)$.

Os dados apresentados na Tabela 3 mostram os diagnósticos referidos pelos entrevistados e a presença de febre no quadro sintomático que levou à prescrição do antibiótico. Para a menor faixa etária (0-10 anos), prevaleceram as infecções com comprometimento pulmonar, perfazendo $34,2 \%$ das prescrições e as orofaríngeas com $26,3 \%$ das infecções. Esses dois grupos diferiram significativamente de todas as outras infecções referidas dentro da faixa etária $(p<0,05)$. Esse comportamento se mantém para as outras faixas etárias, com exceção das infecções urinárias que apresentam aumento de incidência a partir da faixa etária 10 a 20 anos.

Indagou-se aos usuários de antibióticos se houve a presença de febre no quadro de sintomas que os levou a procurar assistência médica. Os resultados relacionam a febre com a infecção referida (primeira coluna) e a faixa etária estudada (última linha). De todas as prescrições para infecções orodentais, apenas 9,3\% dos pacientes apresentaram febre, indicando excessivo uso profilático de antibióticos nessa situação. Com relação às faixas etárias, nota-se que na faixa etária $0-10$ anos houve presença de febre em $59,7 \%$ dos pacientes tratados. Esse percentual decresce significativamente nas maiores faixas etárias, chegando a $22,4 \%$ nos pacientes com mais de 60 anos.

A Tabela 4 apresenta os grupos de antibióticos utilizados no tratamento das infecções. As penicilinas, independentemente do diagnóstico referido, foram as mais utilizadas $(45,1 \%)$, seguidas das cefalosporinas $(26,4 \%)$, quinolonas $(14,6 \%)$, sulfas e macrolídeos. Comparando a escolha do antibiótico com as infecções referidas, percebe-se que apenas nas infecções locais e nas urinárias as 
TABELA 1 - Características demográficas e de saúde da população estudada, Sorocaba, São Paulo, 2006 (no=03).

\begin{tabular}{|c|c|c|c|c|c|c|c|c|c|c|}
\hline \multirow[b]{3}{*}{ Faixa etária (anos) } & \multicolumn{4}{|c|}{ Gênero } & \multirow{2}{*}{\multicolumn{2}{|c|}{$\begin{array}{l}\text { Doença } \\
\text { crônica }\end{array}$}} & \multirow{2}{*}{\multicolumn{2}{|c|}{$\begin{array}{l}\text { Uso de outro } \\
\text { medicamento }\end{array}$}} & \multirow{2}{*}{\multicolumn{2}{|c|}{ Total geral $^{*}$}} \\
\hline & \multicolumn{2}{|c|}{ feminino } & \multicolumn{2}{|c|}{ masculino } & & & & & & \\
\hline & $\mathrm{n}^{\circ}$ & $\%$ & $\mathrm{n}^{\mathrm{o}}$ & $\%$ & $\mathrm{n}^{\mathrm{o}}$ & $\%$ & $\mathrm{n}^{\mathrm{o}}$ & $\%$ & $\mathrm{n}^{\circ}$ & $\%$ \\
\hline 0 a 10 & 62 & 27,9 & 52 & 28,7 & 20 & 17,5 & 29 & 25,4 & 114 & $28,3^{a}$ \\
\hline 10 a 20 & 20 & 9,0 & 26 & 14,4 & 10 & 21,7 & 11 & 23,9 & 46 & $11,4^{b}$ \\
\hline 20 a 30 & 36 & 16,2 & 23 & 12,7 & 9 & 15,3 & 15 & 25,4 & 59 & $14,6^{b}$ \\
\hline 30 a 40 & 25 & 11,3 & 19 & 10,5 & 8 & 18,2 & 12 & 27,3 & 44 & $10,9^{b}$ \\
\hline 40 a 50 & 31 & 14,0 & 19 & 10,5 & 22 & 44,0 & 17 & 34,0 & 50 & $12,4^{b}$ \\
\hline 50 a 60 & 22 & 9,9 & 19 & 10,5 & 22 & 52,6 & 24 & 58,5 & 41 & $10,2^{b}$ \\
\hline$\geq 60$ & 26 & 11,7 & 23 & 12,7 & 34 & 69,4 & 29 & 59,2 & 49 & $12,2^{b}$ \\
\hline Total geral & 222 & 55,1 & 181 & 44,9 & 125 & 31,0 & 137 & 34,0 & 403 & 100,0 \\
\hline
\end{tabular}

Letras distintas diferem entre si em nível de $5 \%$ de significância.

TABELA 2 - Uso prévio de antibióticos segundo o grupo utilizado e a faixa etária da população estudada, Sorocaba, São Paulo, 2006 (n⿳o=403).

\begin{tabular}{|c|c|c|c|c|c|c|c|}
\hline & Uso prévio & Penicilinas & Cefalosporinas & Macrolídeos & Sulfas & Quinolonas & Não se lembra \\
\hline Faixa etária (anos) & $\%$ & $\%$ & $\%$ & $\%$ & $\%$ & $\%$ & $\%$ \\
\hline 0 a 10 & 44,7 & 67,3 & 17,3 & 0,0 & 7,7 & 0,0 & 7,7 \\
\hline 10 a 20 & 37,0 & 58,8 & 23,5 & 0,0 & 0,0 & 11,8 & 5,9 \\
\hline 20 a 30 & 20,3 & 66,7 & 22,2 & 0,0 & 0,0 & 0,0 & 11,1 \\
\hline 30 a 40 & 36,4 & 12,5 & 6,3 & 12,5 & 43,8 & 6,3 & 18,8 \\
\hline 40 a 50 & 52,0 & 29,2 & 25,0 & 0,0 & 4,2 & 12,5 & 29,2 \\
\hline 50 a 60 & 31,7 & 27,3 & 9,1 & 0,0 & 18,2 & 18,2 & 27,3 \\
\hline$\geq 60$ & 38,8 & 33,3 & 8,3 & 0,0 & 25,0 & 0,0 & 33,3 \\
\hline Média & 38,2 & 47,5 & 17,0 & 1,4 & 12,1 & 5,7 & 16,3 \\
\hline
\end{tabular}

TABELA 3 - Presença de febre no quadro sintomático segundo a localização topográfica da infecção e a faixa etária (anos) da população estudada, Sorocaba, São Paulo, 2006 ( $\left.\mathbf{n}^{\mathrm{o}}=403\right)$.

\begin{tabular}{|c|c|c|c|c|c|c|c|c|c|}
\hline & Presença de febre & 0 a 10 & 10 a 20 & 20 a 30 & 30 a 40 & 40 a 50 & 50 a 60 & $\geq 60$ & Média \\
\hline Infecções/faixa etária & $\%$ & $\%$ & $\%$ & $\%$ & $\%$ & $\%$ & $\%$ & $\%$ & $\%$ \\
\hline Orodentais & $9,3^{\mathrm{a}}$ & $2,6^{\mathrm{c}}$ & $8,7^{\mathrm{b}}$ & $23,7^{\mathrm{a}}$ & $6,8^{b, c}$ & $10,0^{b}$ & $7,3^{a}$ & - & $8,1^{\mathrm{c}}$ \\
\hline Gastrintestinais & $63,6^{\mathrm{C}}$ & $4,3^{b, c}$ & - & $1,6^{\mathrm{C}}$ & $4,5^{b, c}$ & - & $2,4^{b}$ & $4,0^{b}$ & $2,8^{\mathrm{d}}$ \\
\hline Locais (tópicas) & $23,3^{a}$ & $5,2^{b, c}$ & $19,5^{a, b}$ & $1,6^{\mathrm{c}}$ & $18,1^{\mathrm{a}, \mathrm{b}}$ & $28,0^{\mathrm{a}}$ & $19,5^{b}$ & $28,5^{\mathrm{a}}$ & $14,6^{b}$ \\
\hline Orofaríngeas & $62,3^{c}$ & $26,3^{a}$ & $23,9^{\mathrm{a}}$ & $10,1^{b, c}$ & $11,3^{b}$ & $10,0^{b}$ & $4,8^{a}$ & $4,0^{b}$ & $15,1^{b}$ \\
\hline Otites & $58,3^{\mathrm{C}}$ & $7,8^{b, c}$ & $2,1^{b}$ & $1,6^{\mathrm{C}}$ & $2,2^{\mathrm{c}}$ & 一 & - & - & $3,0^{\mathrm{d}}$ \\
\hline Outras & $23,1^{\mathrm{a}}$ & $10,5^{b}$ & $10,8^{a, b}$ & $11,8^{a, b}$ & $6,8^{b, c}$ & $14,0^{a, b}$ & $17,0^{a, b}$ & $22,4^{\mathrm{a}}$ & $12,6^{b}$ \\
\hline Pulmonares & $56,1^{\mathrm{c}}$ & $34,2^{\mathrm{a}}$ & $8,7^{\mathrm{b}}$ & $20,3^{a, b}$ & $29,5^{\mathrm{a}}$ & $22,0^{a, b}$ & $21,9^{\mathrm{a}}$ & $20,4^{\mathrm{a}}$ & $24,7^{\mathrm{a}}$ \\
\hline Sinusites & $66,7^{\mathrm{c}}$ & $5,2^{b, c}$ & $8,7^{\mathrm{b}}$ & $8,4^{b, c}$ & $2,2^{\mathrm{c}}$ & - & $4,8^{b}$ & - & $4,5^{\mathrm{d}}$ \\
\hline Urinárias & $22,0^{\mathrm{a}}$ & $3,5^{c}$ & $17,3^{a, b}$ & $20,3^{a, b}$ & $18,1^{a, b}$ & $16,0^{a, b}$ & $21,9^{\mathrm{a}}$ & $20,4^{\mathrm{a}}$ & $14,6^{b}$ \\
\hline Presença de febre & & $59,7^{\mathrm{a}}$ & $41,3^{b}$ & $39,0^{b, c}$ & $36,4^{b, c}$ & $24,0^{b, c}$ & $29,3^{b, c}$ & $22,4^{\mathrm{c}}$ & $39,9 \mathrm{~b}$ \\
\hline
\end{tabular}

* Letras distintas diferem entre si em nível de $5 \%$ de significância dentro da faixa etária relativa.

TABELA 4 - Grupos de antibióticos prescritos para tratamento das infecções referidas, Sorocaba, São Paulo, 2006 (n⿳ō=403).

\begin{tabular}{|c|c|c|c|c|c|}
\hline & Penicilinas & Cefalosporinas & Quinolonas & Sulfas & Macrolídeos \\
\hline Infecções referidas & $\%$ & $\%$ & $\%$ & $\%$ & $\%$ \\
\hline Orodentais & $68,7^{a}$ & $28,1^{b}$ & $0,0^{\mathrm{C}}$ & $3,1^{\mathrm{c}}$ & $0,0^{\mathrm{C}}$ \\
\hline Gastrintestinais & $36,3^{\mathrm{a}}$ & $27,3^{a, b}$ & $9,1^{a, b}$ & $27,3^{a, b}$ & $0,0^{b}$ \\
\hline Locais & $25,8^{\mathrm{a}}$ & $56,9^{\mathrm{b}}$ & $10,3^{c}$ & $5,2^{c}$ & $1,7^{\mathrm{c}}$ \\
\hline Orofaríngeas & $61,6^{\mathrm{a}}$ & $20,0^{b}$ & $0,0^{\mathrm{c}}$ & $11,7^{b, d}$ & $6,7^{\mathrm{d}}$ \\
\hline Otites & $66,6^{\mathrm{a}}$ & $0,0^{b}$ & $8,3^{b}$ & $0,0^{b}$ & $25,0^{b}$ \\
\hline Outras & $38,0^{\mathrm{a}}$ & $26,0^{a, b}$ & $16,0^{b, c}$ & $8,0^{\mathrm{C}}$ & $12,0^{b, c}$ \\
\hline Pulmonares & $60,2^{\mathrm{a}}$ & $21,4^{b}$ & $4,1^{\mathrm{c}}$ & $7,1^{\mathrm{c}}$ & $7,1^{\mathrm{c}}$ \\
\hline Sinusites & $61,1^{\mathrm{a}}$ & $16,7^{b}$ & $5,6^{b}$ & $0,0^{b}$ & $16,7^{b}$ \\
\hline Urinárias & $6,9^{\mathrm{a}, \mathrm{c}}$ & $19,0^{\mathrm{a}}$ & $63,8^{b}$ & $6,9^{\mathrm{a}, \mathrm{c}}$ & $3,4^{\mathrm{c}}$ \\
\hline Total & $45,1^{a}$ & $26,4^{b}$ & $14,6^{c}$ & $7,3^{d}$ & $6,6^{d}$ \\
\hline
\end{tabular}

${ }^{*}$ Letras distintas diferem entre si em nível de $5 \%$ de significância dentro das infecções relativas. 
penicilinas não foram as mais utilizadas. Prevaleceu o uso de cefalosporinas $(p<0,05)$ nas infecções locais e de quinolonas nas infecções urinárias $(\mathrm{p}<0,05)$.

Os dados apresentados na Tabela 5 mostram o tempo de terapêutica em função do medicamento prescrito e da infecção referida. Com relação aos fármacos, o grupo dos macrolídeos foi o único que apresentou diferença estatisticamente significante $(\mathrm{p}<0,05)$ no tempo de terapêutica, com tempo médio de emprego em torno de 5,4 dias. Quanto às infecções, nota-se que, em média (dias), apenas as infecções pulmonares $(10,1)$ e sinusites $(11,4)$ apresentaram diferença $(\mathrm{p}<0,05)$ em relação às infecções urinárias $(7,4)$, locais $(7,4)$ e orodentais $(7,2)$.

TABELA 5 - Tempo de tratamento prescrito (dias) segundo o grupo de antibióticos e as infecções referidas pela população estudada, Sorocaba, São Paulo, 2006 ( $\left.\mathbf{n}^{\mathrm{o}}=403\right)$.

\begin{tabular}{lrrrrr}
\hline & Mínimo & Máximo & Mediana & Média $^{*}$ & DP \\
\hline Antibióticos & 3 & 15 & 7 & $8,3^{\mathrm{a}}$ & 3,4 \\
Sulfas & 1 & 15 & 10 & $8,8^{\mathrm{a}}$ & 2,7 \\
Penicilinas & 2 & 15 & 7 & $7,9^{\mathrm{a}}$ & 1,9 \\
Cefalosporinas & 1 & 15 & 6 & $5,4^{\mathrm{b}}$ & 3,2 \\
Macrolídeos & 3 & 15 & 7 & $7,7^{\mathrm{a}}$ & 3,1 \\
Quinolonas & & & & & \\
\hline Infecções & 7 & 10 & 7 & $7,2^{\mathrm{d}}$ & 0,7 \\
Orodentais & 7 & 14 & 7 & $8,7^{\mathrm{c}, \mathrm{d}}$ & 2,2 \\
Gastrintestinais & 1 & 15 & 7 & $7,4^{\mathrm{d}}$ & 2,6 \\
Locais & 6 & 14 & 7 & $8,4^{\mathrm{c}, \mathrm{d}}$ & 1,8 \\
Orofaríngeas & 3 & 10 & 10 & $8,9^{\mathrm{c}, \mathrm{d}}$ & 2,1 \\
Otites & 2 & 21 & 10 & $9,1^{\mathrm{c}}$ & 3,5 \\
Pulmonares & 15 & 10 & $10,4^{\mathrm{c}}$ & 3,4 \\
Sinusites & 3 & 15 & 7 & $7,4^{\mathrm{d}}$ & 3,0 \\
\hline Urinárias & 1 & & & & \\
\hline
\end{tabular}

* Média aritmética: Letras distintas diferem entre si em nível de $5 \%$ de significância (Tukey-Kramer), DP: desvio-padrão.

\section{DISCUSSÃO}

Com relação ao perfil dos usuários deste estudo, destaca-se o grande número de crianças (0-10 anos) tratadas com antibióticos (Tabela 1). A maior utilização de antibióticos nessa faixa etária devese ao sistema imunológico imaturo de crianças, além da facilidade de transmissão de agentes infecciosos nessa faixa etária em função da aglomeração e contato muito próximo em creches e escolas. Outro fator de importância a ser considerado na avaliação do uso de antibióticos em crianças é o emprego empírico pela classe médica, especialmente nas infecções respiratórias agudas, onde a dificuldade em se diferenciar a etiologia viral ou bacteriana, leva à prescrição profilática, inócua do antibiótico ${ }^{6,10,11}$. Outros estudos mostram esse mesmo perfil de distribuição entre faixas etárias ${ }^{12}$.

Estudo realizado na Cidade de São Paulo, no ano de 1997, mostra que em torno de $68 \%$ das prescrições de antibióticos para o tratamento de infecções respiratórias agudas pediátricas foram inadequadas, sendo que a grande maioria das crianças apresentou somente um resfriado comum, associado à etiologia viral ${ }^{6}$.

Outro dado preocupante encontrado no presente estudo foi o grande percentual de usuários com utilização prévia de antibióticos no período de seis meses, o que equivaleria a quatro prescrições por ano (Tabela 2). Essa média ultrapassa, e muito, a média de países como os Estados Unidos, com 0,46 prescrições/habitante/ano ${ }^{12}$. Esse padrão de prescrição acarreta desperdício de dinheiro público e privado na aquisição de medicamentos, mau emprego desses fármacos por parte dos prescritores, não promovendo a cura das infecções ou permitindo seu recrudescimento e ainda; o que é mais grave, tornando nosso arsenal terapêutico antimicrobiano cada vez mais ineficaz, em função de seu uso inadequado.

No quadro sintomático, pôde-se observar que apenas 39,9\% dos pacientes apresentaram febre, ou seja, $60 \%$ das pessoas fizeram uso de antibiótico sem apresentar esse sintoma. Mesmo sabendo que alguns pacientes podem não apresentar febre em infecções bacterianas, esse grande número de prescrições revela o excessivo uso de antibióticos como agente profilático. A literatura mostra que esta forma de uso é ineficaz, na maioria das vezes, para a prevenção de infecções e que não é capaz de impedir o agravamento de uma possível infecção severa ${ }^{13-15}$.

Quanto à idade, nota-se que na faixa etária de 60 anos ou mais, $77,6 \%$ dos pacientes que receberam antibióticos não tinham febre quando receberam essa prescrição. Mesmo considerando a maior ocorrência de quadros infecciosos sem febre nos idosos, esse percentual parece muito elevado.

Embora a faixa etária " 0 a 10 anos" seja a que recebeu prescrições com o maior percentual de presença de febre $(59,7 \%)$, o índice de $40 \%$ de crianças sem febre recebendo antibióticos mostra-se muito elevado. Trabalhos conduzidos em outros países apresentaram padrões de prescrição para antibióticos em crianças e relacionaram o mau uso, principalmente à formação dos prescritores ${ }^{16,17}$. Bharathiraja et $\mathrm{al}^{14}$ avaliaram, coincidentemente, 403 prescrições (apenas pediatria) e relacionaram-nas não às doenças ou aos pacientes, mas aos prescritores. Os dados mostram que nos mesmos quadros clínicos, pediatras prescreveram antibióticos em $60 \%$ dos quadros, contra $95,5 \%$ dos médicos sem formação pediátrica. Nesse mesmo sentido, médicos com mais de 20 anos de formação prescreveram antibióticos em $44,2 \%$ das situações clínicas contra $88,7 \%$ de médicos com menos de 20 anos de formação, nas mesmas circunstâncias ${ }^{16}$.

$\mathrm{Na}$ análise dos dados referentes à presença de febre e ao tipo de infecção, temos que, nas infecções orodentais, apenas 9,3\% dos pacientes apresentaram febre. Esses resultados indicam o uso abusivo desses medicamentos, com padrão de utilização eminentemente profilático. Alguns autores têm relatado que o cirurgião dentista deveria apurar técnicas cirúrgicas, trabalhar em condições de assepsia e não transferir ao medicamento a responsabilidade da não contaminação ou infecção da ferida cirúrgica ${ }^{18}$.

Com relação aos resultados apresentados na Tabela 4, percebese que os agentes beta-lactâmicos (penicilinas e cefalosporinas) continuam sendo os fármacos de preferência em quase todas as infecções, com exceção das infecções urinárias, que por seus perfis farmacocinéticos inadequados, dão lugar às quinolonas, mais adequadas para esse quadro infeccioso. Com relação ao uso de quinolonas, na população estudada, observou-se o seu emprego principalmente em infecções urinárias $(63,8 \%)$, embora a literatura descreva a ampliação de sua utilização para as infecções pulmonares com sucesso terapêutico ${ }^{19,20}$.

Para se atingir sucesso terapêutico em infecções bacterianas, há necessidade de se fazer o diagnóstico adequado, com a presunção, ou quando possível confirmação do agente etiológico. Depois de estabelecido o diagnóstico, a escolha do fármaco deve levar em consideração a sensibilidade do agente etiológico, além do perfil 
farmacocinético. Após a escolha do fármaco, deve-se eleger um esquema posológico adequado, que além da dose e intervalos, inclui o tempo de terapêutica.

No presente trabalho, os esquemas adotados para as otites e sinusites, apresentaram média de tempos de terapêutica em 8,9 e 10,4 dias respectivamente. Consensos nacionais ${ }^{21,22}$ e protocolos internacionais consagrados ${ }^{23}$ têm recomendado esquemas de 10 dias ininterruptos de terapêutica para essas infecções. Em otites, o tempo médio da prescrição ( 8,9 dias) no presente trabalho, esteve abaixo do recomendado (10 dias), com $25 \%$ das prescrições não atingindo a preconização. Para as sinusites, embora a média esteja dentro do recomendado, verificou-se $22 \%$ das prescrições com tempo inferior ao preconizado. Importante observar que, especialmente, nas sinusites observou-se grande diferença no tempo de terapêutica prescrito com desvio padrão de 3,4 dias, variando entre 3 e 15 dias.

É fundamental a adoção e o seguimento de protocolos terapêuticos regionais, buscando padronizar a terapêutica, evitando recidivas a agravamento dos quadros levando pacientes a internações e intervenções cirúrgicas.

Ao avaliar-se o tempo de terapêutica empregado em função do fármaco, percebe-se que apenas os macrolídeos apresentaram tempo médio ( 5,4 dias) de terapêutica inferior $(\mathrm{p}<0,05)$ a todos os outros grupos de fármacos estudados. Essa diferença é explicada em função da introdução de novos macrolídeos (roxitromicina, claritromicina e azitromicina), que embora apresentem pouco ou nenhum benefício no espectro de atividade do grupo, trouxeram grande vantagem no reduzido tempo de terapêutica empregado. A azitromicina tem sido utilizada com relativo sucesso em infecções de vias aéreas superiores, administrada uma vez ao dia, apenas por três dias, o que significa apenas três doses para todo o tratamento, trazendo maior conforto ao paciente e consequente adesão ao tratamento ${ }^{24}$.

Concluindo, muitos profissionais de saúde ainda não se deram conta do grande problema que é, para a saúde pública, o mau uso de antibióticos e a resistência bacteriana. Há necessidade de melhores critérios na prescrição, dispensação e uso desses fármacos sob pena de, em alguns anos, não haver medicamentos disponíveis eficazes no combate às infecções. Informações sobre índices de resistência, seu impacto social e econômico precisam atingir prescritores, dispensadores e a população em geral para que todos se tornem cúmplices no combate à resistência bacteriana.

Concluiu-se que ainda é muito grande a utilização de antibióticos sem critérios aceitáveis. A inexistência ou a não utilização de protocolos terapêuticos têm resultado em grande diferença nos padrões de prescrição, levando a insucesso terapêutico e recidivas de infecções - situações frequentemente encontradas no presente estudo.

\section{CONFLITO DE INTERESSE}

Os autores declaram não haver nenhum tipo de conflito de interesse.

\section{SUPORTE FINANCEIRO}

Fundação de Amparo à Pesquisa do Estado de São PauloFAPESP-Processo n. 04-11685-5.

\section{REFERÊNCIAS}

1. McGowan JE. Economic impact of antimicrobial resistance. Emerg Infect Dis 2001; 7: 286-292.

2. Niederman MS. Principles of appropriate antibiotic use. Int J Antimicrob Agents 2005; 26: 170-175.

3. Shea KM. Antibiotic resistance: what is the impact of agricultural uses of antibiotics on children's health? Pediatrics 2003; 112: 253-258.

4. Haak H. Padrões de consumo de medicamentos em dois povoados da Bahia (Brasil). Rev Saúde Pública 1989; 23: 143-151.

5. Ladd E. The use of antibiotics for viral upper respiratory tract infections: an analysis of nurse practitioner and physician prescribing practices in ambulatory care, 1997-2001. J Am Acad Nurse Pract 2005; 17: 416-424.

6. Bricks LF. Judicious use of medication in children. J Pediatr (Rio) 2003; 79: 107-114.

7. Scheifele D, Halperin S, Pelletier L, TalbotJ, Vaudry W,Jadavji T, Law B, MacDonald N, Wang E, Mills E, Level MH, Déry P, Morris R, Delage G. Update on penicillin resistance rates among pneumococci causing invasive infection in children Canada, 1998 (abstract). Paediatr Child Health 2000; 5 (suppl A): 102, p.37A.

8. Programa das Nações Unidaspara o Desenvolvimento. Atlas do desenvolvimentohumano no Brasil. Rio de Janeiro: PNUD, IPEA, Fundação João Pinheiro; 2003. Disponível em: <http://www.pnud.org.br/atlas/ranking/IDH-M\%2091\%2000\%20Ranking\%20 decrescente\%20(pelos\%20dados\%20de\%202000).htm>. Acesso em: 12 fev 2009.

9. Cochran WG. Técnicas de Amostragem. $1^{\text {st }}$ ed. Rio de Janeiro: Fundo de Cultura, 1974.

10. Bagshaw SM, Kellner JD. Beliefs and behaviours of parents regarding antibiotic use by children. Can J Infect Dis 2001; 12: 93-97.

11. Jacobs RF. Judicious use of antibiotics for common pediatric respiratory infections. Pediatr Infect Dis J 2000; 19: 938-943.

12. McCaig LF, Besser RE, Hughes JM. Antimicrobial Drug Prescription in Ambulatory Care Settings, United States 1992-2000. Emerg Infect Dis 2003; 9: 432-437.

13. Barden LS, Dowell SF, Schwartz B, Lackey C. Current attitudes regarding use of antimicrobial agents: results from physician's and parent's focus group discussion. Clin Pediatr (Phila) 1998; 37: 665-671.

14. Bauchner H, Pelton SI, Klein JO. Parents, physicians, and antibiotic use. Pediatrics 1999; 103: 395-401.

15. Gadomski AM. Potential interventions for preventing pneumonia among young children: lack of effect of antibiotic treatment for upper respiratory infections. Pediatr Infect Dis J 1993; 12: 115-120.

16. Bharathiraja R, Sivakumar S, Chelliah LR, Suresh S, Senguttuvan M. Factors affecting antibiotic prescribing pattern in pediatric practice. Indian J Pediatr 2005; 72: 877-897.

17. Mohan S, Dharamraj K, Dindial R, Mathur D, ParmasadV, Ramdhanie J, Matthew J, Pinto Pereira LM. Physician behavior for antimicrobial prescribing for pediatric upper respiratory tract infections: a survey in general practice in Trinidad, West Indies. Ann Clin Microbiol Antimicrob 2004; 3: 1-8.

18. Groppo FC, Del Fiol FS, Andrade ED. Profilaxia e tratamento de infecções bacterianas. In: Andrade ED, editor. Terapêutica medicamentosa em odontologia. $2^{\text {nd }}$ edition. São Paulo: Artes Médicas; 2006.

19. Blasi F, Tarsia P, Cosentini R, Cazzola M, Allegra L. Therapeutic potential of the new quinolones in the treatment of lower respiratory tract infections. Expert Opinion on Investigational Drugs 2003; 12: 1165-1167.

20. Grossman RF. The role of quinolones in upper respiratory tract infections. Curr Infect Dis Rep 2001; 3: 224-232.

21. Consenso sobre otites médias. Rev Bras Otorrinolaringol 1999; 65: 1-27.

22. Mello Jr JF. Diretrizes brasileiras de rinossinusites. Rev Bras Otorrinolaringol 2008; 74: 1-59.

23. Gilbert DN, Moellering Jr RC, Eliopoulos GM, Sande MA. The Sanford guide to antimicrobial therapy. $38^{\text {th }}$ edition. Sperryville: Antimicrobial Therapy; 2008.

24. Paris R, Confalonieri M, Dal Negro R, Ligia GP, Mos L, Todisco T, Rastelli V, Perna G, Cepparulo M. Efficacy and safety of azithromycin $1 \mathrm{~g}$ once daily for 3 days in the treatment of community-acquired pneumonia: an open-label randomized comparison with amoxicillin-clavulanate $875 / 125 \mathrm{mg}$ twice daily for 7 days. J Chemother 2008; 20: 77-86. 